\title{
The effect of drug abuse on body mass index in Hispanics with and without HIV infection
}

\author{
Janet E Forrester*, Katherine L Tucker and Sherwood L Gorbach \\ Department of Family Medicine and Community Health, Tufts University School of Medicine, 136 Harrison Avenue, \\ Boston, MA 02111 , USA
}

Submitted 27 April 2004: Accepted 21 July 2004

\begin{abstract}
Objective: There is a widely held view that the lower weight of drug abusers is attributable to diet. However, many studies on the dietary intake of drug abusers have failed to find energy insufficiency, while non-dietary factors have rarely been examined. The purpose of this study was to examine non-dietary factors that could affect the weight of drug abusers with and without HIV infection.

Design: Participants were recruited into one of three groups: HIV-positive drug abusers $(n=85)$, HIV-negative drug abusers $(n=102)$ and HIV-positive persons who do not use drugs ('non-drug abusers', $n=98$ ). Non-dietary factors influencing weight included infection with HIV and/or hepatitis, malabsorption, resting energy expenditure and physical activity.

Setting: The baseline data from a prospective cohort study of the role of drug abuse in HIV/AIDS weight loss conducted in Boston, USA.

Subjects: The first 286 participants to enrol in the study.

Results: HIV-positive drug abusers had a body mass index (BMI) that was significantly lower than that of HIV-positive non-drug abusers. The differences in weight were principally differences in fat. In the men, cocaine abuse, either alone or mixed with opiates, was associated with lower BMI, while strict opiate abuse was not. Infection with HIV or hepatitis, intestinal malabsorption, resting energy expenditure and physical activity, as measured in this study, did not explain the observed differences in weight and BMI.

Conclusions: Drug abuse, and especially cocaine abuse, was associated with lower weight in men. However, infection with HIV and/or hepatitis, malabsorption and resting energy expenditure do not explain these findings.
\end{abstract}

There is accumulating evidence that the differences in weight between drug abusers and non-drug abusers cannot be attributed to poor diet. We recently published data from a study locally known as the BIENESTAR study, showing that Hispanic men infected with HIV who were drug abusers had a lower body mass index (BMI) than HIV-positive men who were not drug abusers. Reported energy intake could not explain the difference in BMI among the $\operatorname{men}^{1}$. These findings, consistent with previous studies conducted in other populations by our own group ${ }^{2}$ and others ${ }^{3,4}$, support the notion that diet alone cannot entirely explain the lower weight of drug abusers. In this follow-up report from the BIENESTAR study, we present data on non-dietary factors that might explain the lower weight of drug abusers. Factors examined include infection with HIV and/or hepatitis, malabsorption, resting energy expenditure (REE) and physical activity.

\section{Methods}

\section{Participants and recruitment}

A full description of the study participants and recruitment methods has been published elsewhere ${ }^{1}$. Briefly, participants were recruited into one of three groups: HIVpositive drug abusers, HIV-negative drug abusers and HIV-positive persons who do not use drugs ('non-drug abusers'). All participants were of self-identified Hispanic ethnicity. Study interviews were conducted in Spanish by bilingual, Hispanic personnel. Recruitment was done through outreach in streets, homeless shelters, health clinics and physician offices. Study subjects were paid a stipend of $\$ 50.00$ for their participation. Participants were protected by a Certificate of Confidentiality, issued by the US Department of Health and Human Services. Hispanic adults ( $\geq 18$ years) who spoke Spanish fluently were considered eligible. The exclusion criteria were pregnant 
at recruitment, non-HIV associated malignancies and refusal to sign a consent form to release medical records. All participants gave informed consent. The study was approved by the Institutional Review Board of the Tufts-New England Medical Center.

\section{Assessments}

The data were collected at two clinic visits about 10 days apart. At the first visit, information on housing, HIV history, HIV medications, drug abuse and physical activity were collected by standardised interview. Participants were asked to fast for a minimum of $5 \mathrm{~h}$ prior to the second visit, and were asked not to drink alcohol or do strenuous physical exercise for a period of $48 \mathrm{~h}$ prior to the visit. At the second visit, we measured weight, height, body composition and REE.

Drug use was determined by standardised interview, using a questionnaire that included items related to the type, mode and frequency of drug use. A participant was considered a drug abuser if he/she reported having used any one of heroin, cocaine, 'speedball' (heroin with cocaine) or methadone (prescription or non-prescription use) by any route at least once in the last 6 months. Other drugs, such as amphetamines, inhalants or barbiturates, were not considered in this study because the frequency of their use was low in this population. Persons who reported marijuana use only were classified with the nonusers because marijuana and its legal derivatives are used as appetite stimulants among persons infected with HIV. Self-reported HIV status was confirmed by enzyme-linked immunosorbent assay (ELISA).

\section{Body composition}

We determined body composition by bioelectrical impedance analysis (BIA). Detecting electrodes were placed on the wrist and ankle, and the signal introduction electrodes were placed on the first joint of the middle finger and on the foot just behind the middle toes, following the manufacturer's recommended procedures (RJL Systems Inc., Clinton, MI, USA). We examined subjects for oedema and excluded their data from the analyses if oedema was present at the time of the BIA measures. We used the equations of Lukaski ${ }^{5}$ to derive measures of fat and fat-free mass. We validated the use of the Lukaski equations to measure body composition in this population against body composition measured by dualenergy X-ray absorptiometry (unpublished data).

\section{$\boldsymbol{R E E}$}

REE was determined by indirect calorimetry using a Sensormedic Vmax series spirometer (model 2130; Sensormedic Corp., Yorba Linda, CA, USA). The participant's oxygen consumption $\left(\mathrm{VO}_{2}\right)$ and carbon dioxide production $\left(\mathrm{VCO}_{2}\right)\left(\mathrm{ml} \mathrm{min}^{-1}\right)$ were measured every $30 \mathrm{~s}$ for a period of $15 \mathrm{~min}$ in steady-state conditions, and this information was converted to REE using the modified
Weir equation:

$$
\operatorname{REE}(\mathrm{kcal} / 24 \mathrm{~h})=\left(3.94 \mathrm{VO}_{2}+1.1 \mathrm{VCO}_{2}\right) \times 1.44 .
$$

We used information on gender, age, height and weight in the Harris-Benedict equation ${ }^{6}$ to calculate the predicted REE. We assessed the degree of hypo- or hyper-metabolism by calculating the difference between the measured and predicted REE. All between-group differences in REE were adjusted for fat-free mass.

\section{Malabsorption}

Intestinal malabsorption was measured by the 2-h D-xylose absorption test. Each participant was given $25 \mathrm{~g}$ of D-xylose in water, and the serum levels of D-xylose were measured $2 \mathrm{~h}$ later. Two-hour serum values below $20 \mathrm{mg} \mathrm{dl}^{-1}$ are considered to indicate malabsorption in our hospital.

\section{Physical activity}

To measure physical activity we asked participants in a standardised interview format how many blocks they walked in a typical day. As the data were highly skewed, we report the median, 25th and 75th percentiles and logtransformed the data for the statistical analyses. We also asked about weight lifting or bodybuilding exercises, since drug abusers in our community are often incarcerated in facilities where a gymnasium is available. We began to ask about physical activity at the baseline visit after the study had been running for about 3 years. For this reason, we have incomplete data on these measures.

\section{HIV and bepatitis infection}

HIV RNA was measured by reverse-transcriptase polymerase chain reaction (PCR) with the Roche Amplicor Monitor (Roche Molecular Systems, Somerville, NJ, USA), with a lower detection limit of 400 copies $\mathrm{ml}^{-1}$. CD 4 lymphocyte counts were assessed using a specific monoclonal antibody and fluorescence-activated cellsorting analysis.

The presence in serum of hepatitis B surface antigen was determined with the Genetics Systems HBsAg Enzyme Immunoassay (EIA) 3.0 (Biorad Laboratories, Redmond, WA, USA). Antibody to the hepatitis B surface antigen (anti-HBs) was determined by EIA (DiaSorin Inc., Stillwater, MN, USA). Total antibodies to the hepatitis B core antigen (anti-HBc) were determined by EIA (DiaSorin Inc.). The presence in serum of the antibody to the hepatitis $\mathrm{C}$ virus (anti-HCV) was determined by ELISA (ORTHO HCV Version 3.0; Ortho-Clinical Diagnostics, Inc., Raritan, NJ, USA). The presence in serum of hepatitis $\mathrm{C}$ virus RNA was determined by PCR of CDNA (AMPLICOR Hepatitis C Virus test, Version 2.0; Roche Molecular Systems Inc., Branchburg, NJ, USA).

\section{Statistical analyses}

In the first stage of the analyses we compared BMI, body composition, malabsorption and energy expenditure 
among the three study groups. For the continuous variables with a normal distribution, differences among the groups were tested using the least-squares means option in SAS version 9.0 (SAS Institute, Cary, NC, USA), in the generalised linear models procedure (PROC GLM). Continuous data with a non-normal distribution were logtransformed and the analyses conducted on the transformed data. When transformation did not adequately normalise the data, non-parametric tests were used. HIV viral load was expressed as the median (25th, 75th percentile) of the $\log _{10}$ transformation of the measured viral load. For categorical variables, chi-square or Fisher exact tests were used, where appropriate.

In the second stage of the analyses, we examined the effect of specific drug types on BMI. To do this, we recategorised the data into four mutually exclusive groups based on the specific types of drugs used: (1) users of cocaine only, (2) users of opiates only (mostly heroin or methadone) and (3) multiple-drug users (cocaine and opiates). The fourth group, non-drug abusers, all of whom were HIV-positive, were treated as the reference category.

In addition to examining the effect of specific drug types, we examined other factors that could explain differences in BMI among the specific drug groups, including REE, malabsorption, HIV status, hepatitis C infection, smoking, reported energy intake and physical activity. We did this by adding to models that contained indicator variables for the specific drug-use groups, the variables that predicted BMI and might be in the mechanistic pathway. We expected that the addition of variables in the mechanistic pathway would have an attenuating effect on the differences in BMI among the groups. The multivariate modelling was done in PROC GLM of SAS version 9. We analysed the results from men and women separately.

\section{Results}

Data describing this cohort, including details on dietary intake, weight and BMI, have been published elsewhere ${ }^{1}$.

There were 286 participants enrolled in the study as of 31 December 2003. This number did not include eight eligible participants who did not come to the first appointment and 31 participants (five women and 26 men) who dropped out of the study between the first and second baseline visits. The average BMI of the five women who dropped out was $31.5 \mathrm{~kg} \mathrm{~m}^{-2}$, and the average BMI of the 26 men who dropped out was $27.2 \mathrm{~kg} \mathrm{~m}^{-2}$.

Of the 286 participants enrolled, 206 (72\%) were born in Puerto Rico, 47 (16\%) were born in the mainland USA and the remaining 33 were born in other parts of Latin America or the Caribbean. The proportion of participants who were born in other parts of Latin America or the Caribbean did not differ among the study groups $(P=0.44)$.

The drugs most frequently reported were heroin and cocaine. Forty-eight per cent of the drug users reported using a combination of heroin and cocaine, taken separately or mixed together ('speedball'). Amphetamine use was reported by 13 participants, and always in conjunction with either cocaine or heroin use. Seventyone per cent of the drug abusers reported drug use of at least once per day. Reported marijuana use - not considered drug abuse in this study - or its legal derivatives was higher in the drug abusers than the nondrug abusers (HIV-positive drug abusers 27\%; HIVpositive non-drug abusers 12\%; HIV-negative drug abusers 49\%; $P<0.0001$ ).

Male HIV-positive drug abusers and HIV-positive nondrug abusers were significantly older than the HIVnegative drug abusers (Table 1). The HIV-positive drug abusers and non-drug abusers had been infected with HIV for a similar number of years, and had similar levels of CD4 counts. A smaller proportion of HIV-positive drug abusers were taking highly active anti-retroviral therapy (HAART) than were the HIV-positive non-drug abusers. Male HIVpositive drug abusers weighed less on average and had a lower BMI than did HIV-positive non-drug abusers. The weight differences between the HIV-positive drug abusers and HIV-positive non-drug abusers were attributable to differences in fat. The HIV-positive men, both drug abusers and non-drug abusers, had measured REE values that were significantly higher than REE values predicted using the Harris-Benedict equation. The value of this difference was $+133 \mathrm{kcal}$ or $+556 \mathrm{~kJ}$ per day (standard error (SE): $26 \mathrm{kcal}$ or $108 \mathrm{~kJ}, P<0.0001$ ) for the HIVpositive drug abusers and $+139 \mathrm{kcal}$ or $+582 \mathrm{~kJ}$ per day (SE: $30 \mathrm{kcal}$ or $126 \mathrm{~kJ}, P<0.0001$ ) for the HIV-positive non-drug abusers. The measured REE of the HIV-negative drug abusers did not differ significantly from that predicted by the Harris-Benedict equation $(+28 \mathrm{kcal}$ or $+117 \mathrm{~kJ}$ per day, SE: $25 \mathrm{kcal}$ or $104.6 \mathrm{~kJ}, P=0.27)$. The correlation between REE and fat-free mass in the three groups of men was $r=0.51, P<0.0001 ; r=0.43$, $P<0.0001$; and $r=0.47, P<0.0001$ in the HIV-positive drug abusers, HIV-positive non-drug abusers and HIVnegative drug abusers, respectively. Rates of intestinal malabsorption did not differ among the groups nor did physical activity as measured by bodybuilding activities or the average number of blocks walked per day.

Among the women, the HIV-negative drug abusers were significantly younger than the HIV-positive non-drug abusers (Table 2). On average, the HIV-positive women were overweight, while the HIV-negative women were obese. Differences in weight were attributable to differences in both fat and fat-free mass. The average measured REE did not differ among the three groups of women, nor did the measured REE differ from the predicted REE among any group of women (for HIVpositive drug abusers, difference $=-10 \mathrm{kcal}$ or $-41 \mathrm{~kJ}$ per day (SE: $66 \mathrm{kcal}$ or $276 \mathrm{~kJ}, P=0.88$ ); HIV-positive nondrug abusers, difference $=+30 \mathrm{kcal}$ or $+126 \mathrm{~kJ}$ per day (SE: $40 \mathrm{kcal}$ or $167 \mathrm{~kJ}, P=0.45$ ); and HIV-negative drug 
Table 1 Characteristics of the men stratified by study group

\begin{tabular}{|c|c|c|c|}
\hline Characteristic & $\begin{array}{l}\text { Group } 1 \\
\text { HIV-positive } \\
\text { drug abusers }\end{array}$ & $\begin{array}{c}\text { Group } 2 \\
\text { HIV-positive } \\
\text { non-drug abusers }\end{array}$ & $\begin{array}{c}\text { Group } 3 \\
\text { HIV-negative } \\
\text { drug abusers }\end{array}$ \\
\hline Number in group & 71 & 60 & 81 \\
\hline Age (years) $^{*}$ & $41.0(0.99)^{\mathrm{a}}$ & $40.2(1.1)^{a}$ & $36.7(0.92)$ \\
\hline Years with HIV† & $9(6,12)$ & $8(5,11)$ & - \\
\hline CD4 cell count $†$ & $262(158,452)$ & $367(207,527)$ & $931(692,1140)$ \\
\hline Log viral load† & $3.7(2.3,4.8)$ & $2.3(2.3,3.8)$ & - \\
\hline HAART use & $38(54)^{b}$ & $49(82)$ & - \\
\hline Homeless $\ddagger \S$ & $14(20)$ & $0(0)$ & $47(58)$ \\
\hline Height $(\mathrm{cm})^{*}$ & $171.6(0.85)$ & $170.5(0.86)$ & $169.9(0.73)$ \\
\hline Weight $(\mathrm{kg})^{\star}$ & $74.0(1.4)^{c}$ & $78.8(2.1)$ & $74.6(1.4)$ \\
\hline $\mathrm{BMI}\left(\mathrm{kg} \mathrm{m}^{-2}\right)^{\star}$ & $25.2(0.42)^{d}$ & $27.0(0.66)$ & $25.8(0.46)$ \\
\hline Fat mass $(\mathrm{kg})^{*}$ & $18.9(0.90)^{e}$ & $21.6(1.4)$ & $19.1(0.92)$ \\
\hline Fat-free mass $(\mathrm{kg})^{*}$ & $55.3(0.94)$ & $57.2(1.2)$ & $55.5(0.77)$ \\
\hline Reported dietary energy (kcal day $\left.{ }^{-1}\right)^{\star}$ & $2712(113)$ & 2567 (124) & 2851 (127) \\
\hline Reported dietary energy $\left(\mathrm{kJ} \mathrm{day}^{-1}\right)^{*}$ & $11347(54)$ & $10740(518)$ & $11928(531)$ \\
\hline $\operatorname{REE}\left(\text { kcal day }^{-1}\right)^{*}$ & $1962(26)^{f}$ & $1996(30)^{f}$ & $1897(25)$ \\
\hline $\operatorname{REE}\left(\mathrm{kJ} \mathrm{day}^{-1}\right)^{\star}$ & 8209 (109) & $8351(126)$ & 7937 (105) \\
\hline Predicted REE (kcal day $\left.{ }^{-1}\right)^{\star}$ & $1832(27)$ & $1907(30)$ & $1866(26)$ \\
\hline Predicted REE $\left(\mathrm{kJ} \mathrm{day}^{-1}\right)^{*}$ & 7665 (113) & 7979 (126) & 7891 (109) \\
\hline Malabsorption & $6 / 67(9)$ & $6 / 57(11)$ & $15 / 76(20)$ \\
\hline Bodybuilding exerciseף & $8 / 62(13)$ & $11 / 49(22)$ & 10/75 (13) \\
\hline Blocks walked per day† & $3(0,60)$ & $4(0,20)$ & $7(2,30)$ \\
\hline
\end{tabular}

HAART - highly active anti-retroviral therapy; BMI - body mass index; REE - resting energy expenditure.

*Values are mean (standard error)

$\dagger$ Values are the median (25th, 75th percentile).

$\ddagger$ Values are $n(\%)$.

$\S$ Differences in rates of homelessness were a consequence of recruitment strategies.

If Values are $n / N(\%)$.

${ }^{a}$ Group 1 vs. Group 3, $P=0.002$; Group 2 vs. Group 3, $P=0.02$.

${ }^{\mathrm{b}}$ Group 1 vs. Group 2, $P=0.0007$

${ }^{c}$ Group 1 vs. Group 2, $P=0.04$.

${ }^{\mathrm{d}}$ Group 1 vs. Group 2, $P=0.01$.

${ }^{e}$ Group 1 vs. Group 2, $P=0.05$

${ }^{\dagger}$ Group 1 vs. Group 3, $P=0.07$; Group 2 vs. Group 3, $P=0.01$.

abusers difference $=+62 \mathrm{kcal}$ or $+259 \mathrm{~kJ}$ per day (SE: $57 \mathrm{kcal}$ or $238 \mathrm{~kJ}, P=0.28)$ ). The correlation between REE and fat-free mass in the three groups of women was $r=0.13, P=0.13 ; \quad r=0.50, P=0.002 ;$ and $r=0.32$, $P=0.21$, in the HIV-positive drug abusers, HIV-positive non-drug abusers and HIV-negative drug abusers, respectively. The prevalence of malabsorption was zero or low among all groups of women. There was no difference in reported bodybuilding among the three groups of women. Women who were HIV-positive drug abusers reported walking a greater number of blocks per day on average than did women who were HIV-positive non-drug abusers or HIV-negative drug abusers.

When we examined the effects of the specific types of drugs on BMI we found that, among the men, users of cocaine only and multiple-drug users (cocaine and opiates), but not exclusively opiate users, had significantly lower BMI compared with HIV-positive non-drug abusers (Table 3). There was an appearance of a dose effect such that the users of cocaine alone had a lower BMI than the users of cocaine and opiates combined. However, we found no effect of the frequency of drug use on BMI among the users of cocaine. The lower BMI observed among the men who used cocaine alone or with opiates could not be explained by differences among the groups in reported energy intake, REE, HIV infection, hepatitis C infection, malabsorption or physical activity, as measured in this study. Infection with HIV, the use of HAART, infection with hepatitis $\mathrm{C}$ or hepatitis $\mathrm{C}$ viraemia were not predictors of differences in BMI and therefore were not considered further.

Homelessness was a significant predictor of lower BMI among the men. Since there were no homeless men among the HIV-positive non-drug abusers, we could not add homelessness to models that included the HIVpositive non drug-abusing men. To examine the contribution of homelessness to the differences in BMI, we limited the analyses to the drug abusers. The rates of homelessness did not differ significantly between the opiate only users and the users of drugs that contained cocaine $(P=0.10)$, and therefore did not parallel the observed differences in BMI.

We had too few women to meaningfully examine the effects of the specific types of drugs on BMI. There did not appear to be important differences in BMI between the women who used cocaine with or without other drugs and the women who used exclusively opiates or who were not drug abusers (Table 4). However, it is noteworthy that among all four groups, the women who were cocaine abusers had the lowest BMI. 
Table 2 Characteristics of the women stratified by study group

\begin{tabular}{|c|c|c|c|}
\hline Characteristic & $\begin{array}{c}\text { Group } 1 \\
\text { HIV-infected } \\
\text { drug abusers }\end{array}$ & $\begin{array}{c}\text { Group } 2 \\
\text { HIV-infected } \\
\text { non-drug abusers }\end{array}$ & $\begin{array}{c}\text { Group } 3 \\
\text { HIV-non-infected } \\
\text { drug abusers }\end{array}$ \\
\hline Number in group & 14 & 38 & 21 \\
\hline Age (years) ${ }^{\star}$ & $36.2(1.5)$ & $39.1(1.6)^{\mathrm{a}}$ & $33.0(1.6)$ \\
\hline Years with HIV† & $5(2,9)$ & $6(4,9)$ & - \\
\hline CD4 cell count $\dagger$ & $415(302,491)$ & $394(175,576)$ & $1075(835,1301)$ \\
\hline Log viral load† & $3.0(2.8,3.4)$ & $2.3(2.3,3.7)$ & - \\
\hline HAART use & $4(29)$ & $22(58)$ & - \\
\hline Homeless $\ddagger \S$ & $2(14)$ & $3(8)$ & $5(24)$ \\
\hline Height $(\mathrm{cm})^{*}$ & $162.0(1.8)^{\mathrm{b}}$ & $157.3(1.1)$ & $158.6(1.4)$ \\
\hline Weight $(\mathrm{kg})^{*}$ & $70.4(4.5)$ & $72.0(2.7)$ & 77.7 (3.7) \\
\hline BMI $\left(\mathrm{kg} \mathrm{m}^{-2}\right)^{\star}$ & $26.8(1.7)^{\mathrm{c}}$ & $29.0(1.0)$ & $30.8(1.4)$ \\
\hline Fat mass $(\mathrm{kg})^{*}$ & $23.3(3.2)^{d}$ & $30.3(2.0)$ & $32.3(2.6)$ \\
\hline Fat-free mass $(\mathrm{kg})^{\star}$ & $47.1(2.2)^{\mathrm{e}}$ & $41.7(1.3)$ & $45.4(1.8)$ \\
\hline Reported dietary energy $\left(\mathrm{kcal} \mathrm{day}^{-1}\right)^{*}$ & $2236(152)^{f}$ & $1836(94)$ & $1982(124)$ \\
\hline Reported dietary energy $\left(\mathrm{kJ}^{\mathrm{day}}{ }^{-1}\right)^{*^{\prime}}$ & $9355(636)$ & $7682(393)$ & $8293(519)$ \\
\hline $\operatorname{REE}\left(\text { kcal day }^{-1}\right)^{*}$ & $1560(61)^{\mathrm{g}}$ & $1666(35)$ & $1700(43)$ \\
\hline $\operatorname{REE}\left(\mathrm{kJ} \mathrm{day}^{-1}\right)^{*}$ & $6527(255)$ & $6971(146)$ & $7113(180)$ \\
\hline Predicted REE (kcal day $\left.{ }^{-1}\right)^{*}$ & $1614(51)$ & $1607(31)$ & $1702(42)$ \\
\hline Predicted REE (kJ day $\left.{ }^{-1}\right)^{*}$ & $6753(213)$ & $6724(130)$ & $7121(176)$ \\
\hline Malabsorption & $1 / 14(7)$ & $0 / 38(0)$ & $0 / 20(0)$ \\
\hline Bodybuilding exercise & $1 / 11(9)$ & $0 / 38(0)$ & 2/18 (11) \\
\hline Blocks walked per day† & $6(3,10)^{\mathrm{h}}$ & $3(2,6)$ & $2(1,6)$ \\
\hline
\end{tabular}

HAART - highly active anti-retroviral therapy; BMI - body mass index; REE - resting energy expenditure.

*Values are mean (standard error).

†Values are the median (25th, 75th percentile).

$\ddagger$ Values are $n(\%)$.

$\S$ Differences in rates of homelessness were a consequence of recruitment strategies.

I Values are $n / N(\%)$

a Group 2 vs. Group 3, $P=0.01$.

${ }^{\mathrm{b}}$ Group 1 vs. Group 2, $P=0.04$.

${ }^{\mathrm{c}}$ Group 1 vs. Group 3, $P=0.07$.

Group 1 vs. Group 2, $P=0.07$; Group 1 vs. Group 3, $P=0.04$

${ }^{\mathrm{e}}$ Group 1 vs. Group 2, $P=0.03$.

${ }^{\dagger}$ Group 1 vs. Group 2, $P=0.03$

g Group 1 vs. Group 3, $P=0.01$

${ }^{\mathrm{h}}$ Group 1 vs. Group 3, $P=0.02$.

Table 3 Characteristics of the men stratified by type of drugs used

\begin{tabular}{|c|c|c|c|c|}
\hline Characteristic & $\begin{array}{l}\text { Group } 1 \\
\text { Cocaine } \\
\text { only users }\end{array}$ & $\begin{array}{l}\text { Group } 2 \\
\text { Opiate } \\
\text { only users }\end{array}$ & $\begin{array}{c}\text { Group } 3 \\
\text { Multiple-drug users }\end{array}$ & $\begin{array}{c}\text { Group } 4 \\
\text { HIV-infected } \\
\text { non-drug abusers }\end{array}$ \\
\hline Number in group & 16 & 68 & 68 & 60 \\
\hline Age $\left(\right.$ years) ${ }^{*}$ & $38.6(2.1)$ & $38.5(1.1)$ & $38.9(1.1)$ & $40.2(1.1)$ \\
\hline HIV-infected $†$ & $11(69)$ & $36(53)$ & $24(35)$ & $60(100)$ \\
\hline Homeless $†$ & $4(25)$ & $23(34)$ & $33(49)$ & $0(0)$ \\
\hline Height $(\mathrm{cm})^{*}$ & $169.3(1.7)$ & $170.3(0.82)$ & $171.5(0.82)$ & $170.5(0.86)$ \\
\hline Weight $(\mathrm{kg})^{*}$ & $68.3(3.4)^{a}$ & $76.2(1.6)$ & $73.8(1.6)$ & $78.8(2.1)$ \\
\hline BMI $\left(\mathrm{kg} \mathrm{m}^{-2}\right)^{\star}$ & $23.6(1.1)^{b}$ & $26.2(0.5)$ & $25.2(0.5)^{\mathrm{C}}$ & $27.0(0.66)$ \\
\hline Reported dietary energy (kcal day $\left.{ }^{-1}\right)^{*}$ & $2643(266)$ & 2842 (128) & $2758(127)$ & 2567 (124) \\
\hline Reported dietary energy $\left(\mathrm{kJ} \text { day }{ }^{-1}\right)^{*^{\prime}}$ & $11058(1113)$ & $11891(536)$ & $11539(531)$ & $10740(519)$ \\
\hline $\operatorname{REE}\left(\text { kcal day }^{-1}\right)^{\star}$ & $1861(61)^{d}$ & $1943(31)$ & $1923(31)$ & $1996(30)$ \\
\hline $\operatorname{REE}\left(\mathrm{kJ} \mathrm{day}^{-1}\right)^{*}$ & $7786(255)$ & $8130(130)$ & $8046(130)$ & $8351(126)$ \\
\hline Predicted REE (kcal day $\left.{ }^{-1}\right)^{*}$ & $1753(58)^{\mathrm{e}}$ & $1879(28)$ & $1844(28)$ & $1907(30)$ \\
\hline Predicted REE $\left(\mathrm{kJ} \mathrm{day}^{-1}\right)^{*^{\prime}}$ & $7335(243)$ & $7862(117)$ & 7715 (117) & $7979(126)$ \\
\hline Malabsorption $\ddagger$ & $2 / 16(13)$ & $6 / 62(10)$ & $13 / 65(20)$ & $6 / 57(11)$ \\
\hline Bodybuilding exercise $\ddagger$ & $3 / 14(21)$ & $7 / 57(12)$ & $8 / 66$ (12) & $11 / 49(22)$ \\
\hline Blocks walked per day§ & insufficient data & $5(3,10)$ & $5(3,8)$ & $4(2,10)$ \\
\hline
\end{tabular}

$\mathrm{BMI}$ - body mass index; REE - resting energy expenditure.

*Values are mean (standard error)

† Values are $n(\%)$.

$\ddagger$ Values are $n / N(\%)$

$\S$ Values are the median (25th, 75th percentile).

a Group 1 vs. Group 2, $P=0.03$; Group 1 vs. Group 4, $P=0.006$.

${ }^{b}$ Group 1 vs. Group 2, $P=0.03$; Group 1 vs. Group 4, $P=0.005$.

${ }^{\mathrm{c}}$ Group 3 vs. Group 4, $P=0.01$.

Group 1 vs. Group 4, $P=0.06$

${ }^{e}$ Group 1 vs. Group 2, $P=0.05$; Group 1 vs. Group 4, $P=0.02$. 
Table 4 Characteristics of the women stratified by type of drug used

\begin{tabular}{|c|c|c|c|c|}
\hline Characteristic & $\begin{array}{l}\text { Group } 1 \\
\text { Cocaine } \\
\text { only users }\end{array}$ & $\begin{array}{l}\text { Group } 2 \\
\text { Opiate } \\
\text { only users }\end{array}$ & $\begin{array}{c}\text { Group } 3 \\
\text { Multiple-drug users }\end{array}$ & $\begin{array}{c}\text { Group } 4 \\
\text { HIV-infected } \\
\text { non-drug abusers }\end{array}$ \\
\hline Number in group & 4 & 19 & 12 & 38 \\
\hline Age $\left(\right.$ years) ${ }^{\star}$ & $34.8(4.7)$ & $35.3(1.4)$ & $32.6(2.1)^{\mathrm{a}}$ & $39.1(1.6)$ \\
\hline HIV-infected $\dagger$ & $2(50)$ & $11(58)$ & $1(8)$ & $38(100)$ \\
\hline Homeless $\dagger$ & $0(0)$ & $4(21)$ & $3(25)$ & $3(8)$ \\
\hline Height $(\mathrm{cm})^{\star}$ & 159.5 (3.3) & $160.7(1.5)$ & $158.6(1.9)$ & $157.3(1.1)$ \\
\hline Weight $(\mathrm{kg})^{*}$ & $71.9(9.8)$ & $73.7(4.5)$ & $77.3(5.7)$ & $72.0(2.7)$ \\
\hline $\mathrm{BMI}\left(\mathrm{kg} \mathrm{m}^{-2}\right)^{\star}$ & $28.1(3.6)$ & $28.5(1.6)$ & $30.7(2.1)$ & $29.0(1.0)$ \\
\hline Reported dietary energy $\left(\mathrm{kcal} \mathrm{day}^{-1}\right)^{\star}$ & 2102 (292) & $2053(134)$ & 2125 (169) & $1836(95)$ \\
\hline Reported dietary energy $\left(\mathrm{kJ} \mathrm{day}^{-1}\right)^{\star^{\prime}}$ & $8795(1222)$ & $8590(561)$ & $8891(707)$ & 7682 (397) \\
\hline $\operatorname{REE}\left(\mathrm{kcal}_{\mathrm{day}}{ }^{-1}\right)^{*}$ & $1673(118)$ & $1578(52)^{b}$ & $1805(62)$ & $1665(35)$ \\
\hline REE $\left(\mathrm{kJ} \text { day }^{-1}\right)^{*}$ & 7000 (494) & $6602(218)$ & 7552 (259) & 6966 (146) \\
\hline Predicted REE (kcal day $\left.{ }^{-1}\right)^{\star}$ & 1633 (112) & $1652(52)$ & $1700(65)$ & 1607 (32) \\
\hline Predicted REE $\left(\mathrm{kJ} \mathrm{day}^{-1}\right)^{*^{\prime}}$ & $6832(469)$ & $6912(218)$ & $7113(272)$ & 6724 (134) \\
\hline Malabsorption $\ddagger$ & $0(0)$ & $1(6)$ & $0(0)$ & $0(0)$ \\
\hline Bodybuilding exerciseł & $0 / 3(0)$ & $3 / 17(18)$ & $0 / 9(0)$ & $0 / 30(0)$ \\
\hline Blocks walked per day§ & $4(2,5)$ & $4(2,10)$ & $3(0.5,6)$ & $3(2,8)$ \\
\hline
\end{tabular}

$\mathrm{BMI}$ - body mass index; REE - resting energy expenditure.

* Values are mean (standard error).

† Values are $n(\%)$.

$\ddagger$ Values are $n / N(\%)$.

$\S$ Values are the median (25th, 75th percentile).

a Group 3 vs. Group 4, $P=0.02$.

${ }^{b}$ Group 2 vs. Group 3, $P=0.06$.

\section{Discussion}

In this study, Hispanic men with and without HIV infection who used cocaine alone or with opiates had lower weight and BMI compared with men who used only opiates or men who were HIV-positive but did not use drugs. Users of cocaine alone had the lowest BMI, followed by users of cocaine mixed with opiates. We did not observe an association between the reported frequency of drug abuse and BMI among the cocaine users. However, since the majority of our users were heavy users - over $70 \%$ of the participants reported drug use of at least once per day - we had limited variability in the data to test this association. The differences in BMI observed among the men could not be attributed to differences in reported energy intake, rates of malabsorption, REE, HIV infection, infection with hepatitis $\mathrm{C}$ or physical activity as measured in this study. Men who were HIV-positive had average REE that was significantly higher than that predicted by the Harris-Benedict equation, but REE did not differ between HIV-positive drug abusers and non-drug abusers. Elevated REE in HIVpositive men has been observed previously ${ }^{7-11}$. Neither cocaine nor heroin use was predictive of differences in REE, although we cannot rule out acute effects of these drugs on short-term increases in REE.

The Hispanic women in our study were overweight or obese, on average, although the women who were both HIV-positive and drug abusers tended to have a lower BMI than women who were HIV-positive but not drug abusers or women who were HIV-negative drug abusers. In contrast to the men, the HIV-positive women did not have measured REE values that were elevated significantly

above the predicted values. Although there were small numbers of women on whom to base our conclusions, the magnitude of the differences between measured and predicted REE was smaller in the HIV-positive women than in the men. It is possible that women do not respond to HIV infection with increases in REE to the same extent as men. However, if there is a difference in the biological basis for REE elevation, the mechanism is unknown.

While we were able to confidently eliminate reported energy intake, malabsorption, REE, HIV and hepatitis infection as possible explanations for the lower BMI of the male cocaine abusers, we cannot exclude the effects of non-resting energy expenditure, including physical activity or homelessness.

Homeless participants in this cohort reported an average energy intake greater than that of participants who were not homeless ${ }^{1}$. These findings agree with those of a study of a German homeless population, in which drug abuse and wasting diseases, such as HIV, cancer or tuberculosis, but not food intake, were associated with poor nutritional state ${ }^{4}$. Thus, dietary insufficiency is not an inevitable consequence of homelessness in this setting. Homelessness may be a marker of higher levels of physical activity or a surrogate for exposure to cold. Since none of the HIV-positive non drug-abusing men were homeless, we could not evaluate the attenuating effect of homelessness on the relation between drug abuse and BMI among the men as a whole. However, as the rates of homelessness did not differ significantly between the men who used cocaine and the men who were strictly opiate users, while BMI did, it seems unlikely that homelessness can explain the observed differences in BMI between these groups. 
To measure physical activity we chose not to use the available validated physical activity questionnaires since they were designed to measure moderate to high levels of physical activity, of importance to cardiovascular disease research. They do not measure low levels of physical activity such as walking at a strolling pace, nor do they measure energy expenditure due to fidgeting or exposure to cold. We expected to find that homeless persons walk more than do non-homeless persons since the local homeless shelters do not allow male residents to stay in the facilities during the day, unless there is a weather emergency. Women with children are permitted to stay indoors both day and night. However, for differences in physical activity to plausibly explain the differences in BMI among the specific drug use groups, it would have to be the sort of physical activity that would differ between cocaine users and opiate users.

It is well established that cocaine induces hyperactivity in rodents, although there are fewer studies in humans ${ }^{12,13}$. Small amounts of increased physical activity, such as twitching, if repetitive, can greatly increase overall energy expenditure ${ }^{14}$. Our measures of physical activity would not have captured such small differences among the groups, but such fine levels may, indeed, explain the relatively lower weight and BMI of the cocaine users. Furthermore, the behavioural response to cocaine in animals has been shown to be dependent on gender, which might explain the differences in BMI in relation to cocaine use between the women and the men in our study $^{15-19}$.

The average BMI of the men and women in our study was normal to obese. This reflects the availability of health care for the indigent population and persons with HIV in the Boston area, as well as the high prevalence of overweight and obesity in the US population as a whole. A recent report from Sweden found that the increased prevalence of overweight in that country was also reflected in the drug-abusing population ${ }^{20}$. While low weight is not a threat to the majority of our study participants, for those with low BMI or those who have advanced AIDS, the results of our study suggest that drug abusers, and particularly users of cocaine, may have more difficulty maintaining their weight or more difficulty regaining weight following bouts of AIDS-related illness. Weight loss continues to be a prevalent problem in HIV, even in the era of HAART ${ }^{21}$, and our results suggest that drug abuse contributes to this problem. In countries where HAART is not readily available, we would expect to see a lower BMI in the HIV-positive population in general and in drug abusers in particular, such as was reported in a recent study of drug abusers in Dhaka, Bangladesh ${ }^{22}$.

Overall this study has shown that, among Hispanic men, cocaine abuse is associated with lower weight and BMI. However, the observed differences in BMI cannot be attributed to differences in reported dietary energy intake, REE, malabsorption, or infection with HIV or hepatitis.
Further studies of cocaine abusers to examine the contribution of increased physical activity, including hyperactivity, as well as studies of cocaine-induced metabolic disturbances are warranted.

\section{Acknowledgements}

This study was supported by the National Institute on Drug Abuse (grant nos. DA 11598 and DA14501), the National Institute of Diabetes \& Digestive \& Kidney Diseases (grant no. DK4 5734-07), the Center for AIDS Research (grant no. 1-P308142853) and the Center for Metabolic Research on HIV and Drug Use (grant no. 5 P30 DA013868-02). The General Research Center of the New England Medical Center, Boston, is supported by the Division of Research Resources of the National Institutes of Health (grant no. M01-RR00054).

We thank the study team for their hard work and the participants for their trust.

\section{References}

1 Forrester JE, Tucker KL, Gorbach SL. Dietary intake and body mass index in HIV-positive and HIV-negative drug abusers of Hispanic ethnicity. Public Health Nutrition 2004; 7: 863-700.

2 Forrester JE, Woods MN, Knox TA, Spiegelman D, Skinner SC, Gorbach SL. Body composition and dietary intake in relation to drug abuse in a cohort of HIV-infected persons. Journal of Acquired Immune Deficiency Syndromes and Human Retrovirology 2000; 25: S43-8.

3 Smit E, Graham N, Tang A, Flynn C, Solomon L, Vlahov D. Dietary intake of community-based HIV-1 seropositive and seronegative injecting drug users. Nutrition 1996; 12: 496-501.

4 Langnäse K, Müller MJ. Nutrition and health in an urban homeless population in Germany. Public Health Nutrition 2001; 4: 805-11.

5 Lukaski HC. Use of bioelectrical impedance analysis to assess human body composition: a review. In: Livingston GE, ed. Nutritional Status Assessment of the Individual. Trunbull, CT: Food and Nutrition Press, Inc., 1989; 189-204.

6 Harris JA, Benedict FG. Standard Basal Metabolism Constants for Physiologists and Clinicians; A Biometric Study of Basal Metabolism in Man. Philadelphia, PA: JB Lippincott, 1919; 223.

7 Hommes MJ, Romijn JA, Godfried MH, Schattenkerk JK, Buurman WA, Endert E, et al. Increased resting energy expenditure in human immunodeficiency virus-infected men. Metabolism 1990; 39: 1186-90.

8 Melchior JC, Salmon D, Rigaud D, Bouvet E, Rigaud D, Matheron S, et al. Resting energy expenditure is increased in stable, malnourished HIV-infected patients. American Journal of Clinical Nutrition 1991; 53: 437-41.

9 Grunfeld C, Pang M, Shimizu L, Shigenaga JK, Jensen P, Feingold KR. Resting energy expenditure, caloric intake, and short-term weight change in human immunodeficiency virus infection and the acquired immunodeficiency syndrome. American Journal of Clinical Nutrition 1992; 55: 455-60.

10 Schwenk A, Höffer-Belitz E, Jung B, Kremer G, Burger B, Salzberger B, et al. Resting energy expenditure, weight loss, and altered body composition in HIV infection. Nutrition 1996; 12: 595-601.

11 Shevitz AH, Knox TA, Spiegelman D, Roubenoff R, Gorbach 
SL, Skolnik PR. Elevated resting energy expenditure among HIV-seroinfected persons receiving highly active antiretroviral therapy. AIDS 1999; 13: 1351-7.

12 Schiorring E. Psychopathology induced by 'speed drugs'. Pharmacology, Biochemistry, and Behavior 1981; 14(Suppl. 1): $109-22$.

13 Rosse RB, Fay-McCarthy M, Collins JP Jr, Risher-Flowers D, Alim TN, Deutsch SI. Transient compulsive foraging behavior associated with crack cocaine use. American Journal of Psychiatry 1993; 150: 155-6.

14 Levine JA, Schleusner SJ, Jensen MD. Energy expenditure of non-exercise activity. American Journal of Clinical Nutrition 2000; 72: 1451-4.

15 Peris J, Decambre N, Cole-Hardee ML, Simpkins JW. Estradiol enhances behavioral sensitization to cocaine and amphetamine-stimulated striatal $\left[{ }^{3} \mathrm{H}\right]$ dopamine release. Brain Research 1991; 556: 255-64.

16 Becker JB, Molenda H, Hummer DL. Gender differences in the behavioral response to cocaine and amphetamine. Implications for the mechanisms mediating gender differences in drug abuse. Annals of the New York Academy of Sciences 2001; 937: 172-87.

17 Perrotti LI, Russo SJ, Fletcher H, Chin J, Webb T, Jenab S, et al Ovarian hormones modulate cocaine-induced locomotor and stereotypic activity. Annals of the New York Academy of Sciences 2001; 937: 202-16.

18 Chin J, Sternin O, Wu HB, Fletcher H, Perrotti LI, Jenab S, et al. Sex differences in cocaine-induced behavioral sensitization. Cellular and Molecular Biology 2001; 47: 1089-95.

19 Chin J, Sternin O, Wu HB, Burrell S, Lu D, Jenab S, et al. Endogenous gonadal hormones modulate behavioral and neurochemical responses to acute and chronic cocaine administration. Brain Research 2002; 945: 123-30.

20 Rajs J, Petersson A, Thiblin I, Olsson-Mortlock C, Fredriksson A, Eksborg S, et al. Nutritional status of deceased illicit drug addicts in Stockholm, Sweden - a longitudinal medicolegal study. Journal of Forensic Science 2004; 49: 320-9.

21 Wanke CA, Silva M, Knox TA, Forrester JE, Speigelman D, Gorbach SL. Weight loss and wasting remain common complications in individuals infected with HIV in the era of highly active antiretroviral therapy. Clinical Infectious Diseases 2000; 31: 804-5.

22 Nazrul Islam SK, Jahangir Hossain K, Ahmed A, Ahsan M. Nutritional status of drug addicts undergoing detoxification: prevalence of malnutrition and influence of illicit drugs and lifestyle. British Journal of Nutrition 2002; 88: 507-13. 